\title{
Japan in Australia: Culture, Context and Connections
}

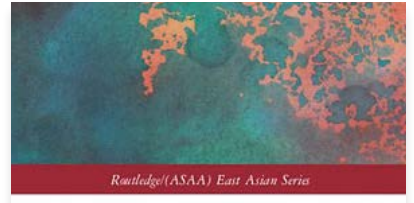

JAPAN IN AUSTRALIA

CULTURE, CONTEXT AND CONNECTION

David Chapman and Carol Hayes

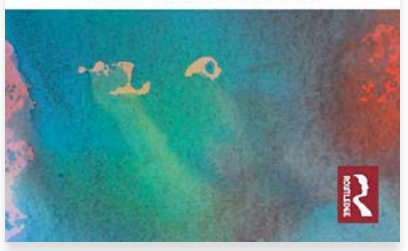

DAVID CHAPMAN AND

CAROL HAYES (EDS).

Routledge (London), 2020.

248 pages.

ISBN 9780367184698.

Reviewed by

Alexander Brown

Japan Women's University and

University of Technology, Sydney

iD https://orcid.org/0000-0002-3582-9658

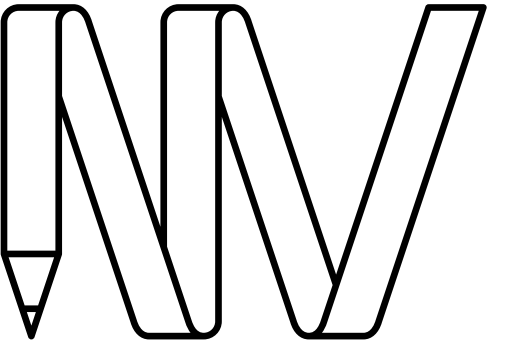

NEW

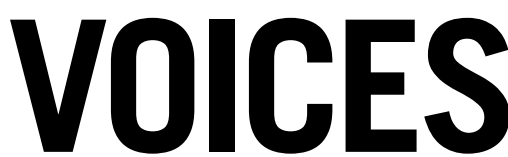

IN JAPANESE STUDIES

\section{KEYWORDS}

Australia; Australia-Japan relations; cross-cultural representation; Japanese Australian; orientalism; transnationalism

$\mathrm{T}$

The edited collection Japan in Australia: Culture, Context and Connections (2020) brings together twelve substantive essays on the cultural history of the Australia-Japan relationship, with a focus on the way Japan is constructed culturally within the Australian context. Published in Routledge's Asian Studies Association of Australia (ASAA) East Asia series, the collection is the result of a conference of the same name held at The University of Queensland in 2016. The conference was one in a series of events marking the fifty-year anniversary of Japanese Studies at the university, a fact which in itself reveals something about the long history of cross-cultural engagement between the two countries. It is dedicated to The Japan Foundation, Sydney which sponsored the 2016 conference and whose funding underpins a significant amount of contemporary Australian research on Japan. It seems appropriate therefore to review the volume in this issue of New Voices in Japanese Studies, the journal established by the Foundation's Sydney Office to support the development of emerging scholars in the field.

The contributions to the volume cover a wide range of topics. In their introductory overview, editors David Chapman and Carol Hayes situate the essays in the collection within a broader history of the modern encounter

\section{JAPANFOUNDATION 8 BRINGING JAPAN TO YOU \\ To link to this article: https://doi.org/10.21159/nvjs.12.r-05}

\section{ISSN 2205-3166}

New Voices in Japanese Studies is an interdisciplinary, peer-reviewed journal showcasing the work of emerging scholars with ties to Australia or New Zealand and research interests in Japan.

All articles can be downloaded free at newvoices.org.au

(c) The Japan Foundation, Sydney and Alexander Brown, 2020.

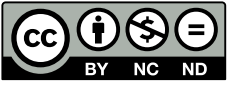

This work is licensed under a Creative Commons Attribution-NonCommercialNoDerivatives 4.0 International License. 
between Australia and Japan since the nineteenth century. Essays by Tomoko Aoyama, Lucy Fraser and Laura Emily Clark explore the notion of AustraliaJapan through a literary lens. Aoyama documents a 1937 visit to Australia by two prominent post-war intellectuals, the siblings Kazuko and Shunsuke Tsurumi, together with their politician father Yūsuke Tsurumi, and the impact the trip had on both. Fraser examines two contemporary Australian adaptations of Yasunari Kawabata's novella The House of the Sleeping Beauties: Venero Armanno's novel Candle Life and Julia Leigh's film Sleeping Beauty. Laura Emily Clark's chapter interrogates the construction of Haruki Murakami in Australian book reviews as both a representative of 'Japanese literature' and an exemplar of 'world literature'. Penny Bailey's chapter on Australian artist Margaret Preston shows how important Japanese woodblock print techniques were to her development of a modern Australian style. Ai Kobayashi and Morris Low both explore sport as an arena of international encounter soon after the end of the Asia-Pacific War. Kobayashi provides a detailed historical account of a 1954 Australian tour by the Yomiuri Giants baseball team, which was intended as a kind of soft-power exercise in diplomacy in a period when Australian attitudes to Japan remained hostile. Low examines Japanese participation in the 1956 Melbourne Olympics, the controversies it generated and the way individual relations between athletes served to stage Japan's readmission to the world community.

Rebecca Hausler's chapter on the transnational production of an Englishdubbed version of Japanese television drama Monkey was particularly close to my heart. Like the author, I grew up watching the show every day after school in the 1980s. Timothy Kazuo Steains' chapter is a fascinating exploration of the work of Nikkei artist Mayu Kanamori and her interrogation of JapaneseAustralian/Australian-Japanese experiences. Koichi Iwabuchi's chapter has a more methodological orientation, proposing the extension of his work on trans-Asian engagement to the study of Australia in Japan. Chihiro Kinoshita Thomson and Ikuo Kawakami bring a focus on language and education to the book, which is particularly relevant given the centrality of language to the teaching of Japanese Studies in Australia. Kinoshita Thomson uses surveys of large Japanese language student cohorts at a Sydney university to argue that students in introductory Japanese courses in Australia are often more concerned with 'consuming' the language learning experience than in gaining the level of mastery of Japanese which would enable them to use it for the more instrumental purposes often envisaged by government funders. Kawakami's chapter makes an argument for a more nuanced understanding of mobility when thinking about young people in Australia who use the Japanese language. She proposes a model of 'Children Crossing Borders' for conceptualising the complex linguistic and physical journeys that growing numbers of young people take between Australia, Japan and often a third or fourth country. Shorter essays by Alan Rix, Roger Pulvers and Vera Mackie provide more personal and impressionistic accounts of Australia-Japan in academia, the arts and the urban landscape respectively.

The book is framed as an exploration of 'Japan in Australia', an approach which attempts to break away from the well-worn scholarly trope of 'the Australia-Japan relationship'. The latter tends to rely upon and to reproduce 
ideas of Australia and Japan as well-defined and largely self-contained nationstates rather than as cultural constructs which are mutually constituted through their interaction with one another. The challenge the editors embrace here reflects Tessa Morris Suzuki's $(2000,22)$ call for an 'anti-Area studies', wherein we treat "people and places in Australia" as part of the research problem, to be "'read'-in an interconnected series of points upon the earth, not only reflecting but becoming objects of reflection". The chapters in Japan in Australia rise to this challenge with varying degrees of success. Penny Bailey's discussion of the influence of woodblock printing on Margaret Preston is a particularly powerful example of how an 'anti-area' approach can undermine the certainty of nation-state borders. In this chapter we see how an AustraliaJapan encounter, mediated in the first instance through the artist's exposure to Japanese prints in Europe, literally shaped the development of what we think of as 'Australian' modern art. Hausler's contribution also introduces other places, namely China and Britain, into the Australia-Japan equation. She argues that it was the encounter between a Chinese story, a Japanese television production, a British dubbing studio and Australian audiences which produced Monkey Magic as a cultural phenomenon in Australia in the 1980s and 1990s. Steains' analysis of Mayu Kanamori's plays and performance pieces that deal with mourning and belonging further complicates the idea of the Australia-Japan encounter as being defined by the encounter between nation states. He shows how the artist engages with Australian Indigenous and Japanese-Indigenous histories, interrogating the difficult question of how migrant communities relate to Indigenous Australia within the broader historical legacies of White Australia and colonialism. Kawakami's contribution, too, hammers away at the Japan-Australia binary by thinking about the complexities and subversive potential of children whose young lives involve multiple crossings of the borders of the international nation-state regime.

The sporting chapters are less successful in breaking out of the Australia-Japan relations frame. Perhaps the inherent nationalism of international sporting events makes it difficult for the authors to avoid reproducing a distinct 'Australia' and 'Japan' in their accounts, though Kobayashi does highlight the ethnically diverse makeup of the Japanese baseball team. Having said that, these chapters are perhaps more concerned with another long-standing problem in Japanese Studies in Australia: the role of orientalism in its perceptions of Japan and the Japanese. Sporting history does help us to understand how perceptions of Japan as the enemy were undermined through sport as cultural diplomacy, helping to enable a new post-war relationship with Japan where friendly rivalry could replace military confrontation. Clark's essay on Murakami also interrogates orientalism in Australian readings of Japan. She demonstrates that Australian reviewers tend to position Murakami as a 'Japanese' author, despite the fact that his novels are frequently criticised in Japan for their lack of Japaneseness, their orientation towards overseas audiences who read them in translation, and their constant references to American pop culture, jazz and classical music. Fraser's piece, too, exposes the sometimes subtle orientalism which remains in contemporary Australian retellings of Kawabata Yasunari's House of the Sleeping Beauties. 
Taken as a whole, the collection provides a model for how to do Japanese Studies in a globalising world. Those chapters such as Bailey's, Hausler's and Kawakami's, which most successfully undermine methodological nationalism in their approach, go beyond 'Australia-Japan' to track the highly mobile people, images, techniques and things that really open up this problematic. In doing so, they raise a question-mark over the usefulness of 'Australia-Japan' as a framework for understanding the transnational construction of Japan in Australia and Australia in Japan. Nevertheless, as academics whose working lives tend to move back and forth between these two countries, it is probably inevitable that we will continue to wonder what our movements in this space mean for the cultural geography of both.

\section{REFERENCES}

\author{
Morris-Suzuki, T. 2000. “Anti-Area Studies.” Communal/Plural 8 (1): 9-23. https://
doi.org/10.1080/13207870050001439. \\ Morris-Suzuki, T. 2000. “Anti-Area Studies.” Communal/Plural 8 (1): 9-23. https://
doi.org/10.1080/13207870050001439.
}

\section{REVIEW}

